\title{
Technology-enhanced feedback
}

\author{
Kathleen Mathieson
}

\section{Source}

Kathleen Mathieson. (2012). Exploring Student Perceptions of Audiovisual Feedback via Screencasting in Online

Courses. American Journal of Distance Education, vol. 26 (3), 143-156. doi:10.1080/08923647.2012.689166.

'At its simplest this involves annotating documents with written comments. However, there are a variety of other options.' Technology-enhanced feedback / audio-visual feedback / screen-casted feedback is a feedback modality that is captured via a digital recording of a computer screen (e.g. screen-cast or screen-capture) and provided to students by higher education tutors/teachers'. 